Research Article

\title{
Autoimmune Hepatitis: Evaluation of Clinical Presentation, Diagnosis and Response to Treatment in Iraqi Patients
}

\author{
Hameed Hussein Al-jameel ${ }^{1,2}$, Najah Kadhim Abbas Alsaadi', $\underline{\text { Satar Jabbar Rahi Algraittee }}^{3}$, \\ Ban Waheed Hussein Bdair \\ ${ }^{1}$ Internal Medicine Department, College of Medicine, Kerbala University, Imam Al-Hussein Medical City, Kerbala, Iraq. \\ ${ }^{2}$ Gastroenterology \& Hepatology Centre, Imam Al-Hussein Medical City, Kerbala, Iraq. \\ ${ }^{3}$ Department of Medical Microbiology and Immunology, College of Medicine, University of Kerbala, Iraq. \\ DOI: https://doi.org/10.24321/0019.5138.202180
}

\section{I $\quad \mathbf{N} \quad \mathbf{F}$}

\section{Corresponding Author:}

Satar Jabbar Rahi Algraittee, Department of Medical Microbiology and Immunology, College of Medicine, Kerbala University, Kerbala, Iraq. E-mail Id:

sattar.rahi72@gmail.com

Orcid Id:

https://orcid.org/0000-0002-2124-3920

How to cite this article:

Al-jameel HH, Alsaadi NKA, Algraittee SJR, Bdair BWH. Autoimmune Hepatitis: Evaluation of Clinical Presentation, Diagnosis and Response to Treatment in Iraqi Patients. J Commun Dis. 2021;53(4):104-113.

Date of Submission: 2021-09-15

Date of Acceptance: 2021-10-05

\section{$\begin{array}{llllllll}\mathbf{A} & \mathbf{B} & \mathbf{S} & \mathbf{T} & \mathbf{R} & \mathbf{A} & \mathbf{C} & \mathbf{T}\end{array}$}

Introduction: Autoimmune hepatitis (AIH) is a chronic heterogeneous inflammatory disease of the liver activated by unknown triggers. The details of its pathogenesis remain unclear. Sufficient data on AlH in terms of epidemiology as well as disease phenotype amongst the Iraqi population is not available.

Objectives: To evaluate and document the experience of Iraqi AIH patients with respect to clinical presentation, diagnosis, treatment and response to treatment in accordance with the IAIHG guidelines.

Method: A prospective study was conducted on patients who attended the Gastroenterology Hepatology Teaching Hospital in Baghdad, Iraq. After examination, many biochemical and pathological parameters were analysed. Liver biopsy, abdominal ultrasound, and upper endoscopy were done.

Results: Among the 70 respondents, jaundice, fatigue, arthralgia, and itching were the major symptoms recorded at presentation. Immunologic findings were positive for ANA (31 patients) and ASMA (25 patients) while hypergammaglobulinemia was recorded in $97 \%$ of all patients. Pre-treatment scoring revealed 56 definite and 14 probable AlH patients while post-treatment scoring yielded 13 definite and 23 probable $\mathrm{AlH}$ patients. Response to treatment showed 6 patients as non-responders, 34 patients $(49 \%)$ exhibited complete response while 30 patients $(43 \%)$ had a partial response.

Conclusions: Iraqi patients with AlH presented late at the advanced stage of the disease with a majority having hypergammaglobulinemia which forms a solid base for disease suspicion. It is recommended that a complementary study with a larger sample size, longer follow-up duration and inclusion of cases of idiopathic hepatitis is needed.

Keywords: Autoimmunity, Autoimmune Hepatitis, Chronic Hepatitis, Cirrhosis, Liver Disease 


\section{Introduction}

Understanding the intrinsic pathogenesis of autoimmune hepatitis $(\mathrm{AIH})$, which is a chronic heterogeneous inflammatory disease of the liver, has over the years continued to pose a challenge to clinicians and researchers. ${ }^{1}$ It is being suggested that unknown triggers initiate a T-cell mediated immune response targeted at the liver, resulting in inflammation and loss of hepatic tolerance of which the mechanisms and the major auto-antigens involved still remain to be unravelled. ${ }^{2,3}$

There is a scarcity of global epidemiological studies on $\mathrm{AlH}$ as many studies were either based on single registries or conducted prior to the standardised criteria introduced by the International Autoimmune Hepatitis Group (IAIHG). ${ }^{4,5}$ However, varying region-specific prevalence have been reported: ranging from as high as 42.9 cases per 100,000 in Alaskan natives, ${ }^{6} 24.5$ cases per 100,000 in New Zealand, ${ }^{4}$ and 11.6 cases per 100,000 in a Spanish population above 14 years old ${ }^{7}$ to as low as 3 cases per 100,000 in the United Kingdom $^{8}$ and 1.9 cases per 100,000 in Norway ${ }^{9}$. In Canada, a recent study utilised the standardised criteria of the IAIHG and reported a nationwide prevalence of 0.23 cases per 100,000 in an exclusively pediatric population. ${ }^{5}$

Interestingly, susceptibility to AlH has been associated with variations in the human leukocyte antigen (HLA) class II HLA-DR3 and HLA-DR4 molecules. ${ }^{10}$ As a result of its genetic aetiology, the epidemiology, as well as clinical presentation of AlH may be greatly influenced by ethnicity and gender. For instance, a high prevalence is observed among North American and northern European whites while relatively low prevalence has been recorded among Asians and some protective alleles identified through a meta-analysis among Latin Americans. ${ }^{11}$ For clinical presentation, African American patients show a higher frequency of cirrhosis at presentation compared to white North Americans. ${ }^{12,13}$ Similarly, Alaskan natives have a higher occurrence of acute icteric disease while Arab patients have cholestasis features. ${ }^{6,14}$

Although AlH affects all gender and age, studies have shown that females have a higher frequency of AlH compared to males in a 4:1 (female: male) ratio. ${ }^{11,15}$ In men, there is early onset as incidence peaks at adolescence while females exhibit a late onset with incidence peak observed post-menopause. ${ }^{4}$

The search for triggers of AlH has proven to be challenging as there could be a number of mechanisms through which liver-derived antigenic sequences could be abnormally targeted by the immune response in individuals genetically predisposed to $\mathrm{AlH}$. Researchers have proposed two probable models:

- The molecular mimicry mechanism where the structural homology between exogenous pathogens and endogenous 'self' components bring about cross-reaction that triggers an immune response. ${ }^{16}$ Supporting this model is the high homology in amino acid sequence shared by hepatitis $C$ virus and the antigenic target of anti-liver/ kidney microsome type 1 (LKM-1) autoantibodies $-10 \%$ of patients with hepatitis C are seropositive to anti-LKM- $1^{17,18}$

- Autoreactivity due to hepatocellular injury, where injuries from conditions like liver cirrhosis or hepatocellular carcinoma expose hidden auto-antigenic epitopes, triggering spontaneous autoantibodies ${ }^{18}$

Potential viral triggers like hepatitis B virus, hepatitis $E$ virus, cytomegalovirus and herpes simplex virus as well as non-viral environmental triggers such as nitrofurantoin and minocycline antibiotics, adalimumab and infliximab have also been proposed, ${ }^{19}$ nonetheless, a universal trigger for AlH still remains to be identified.

Consequent to the ambiguity of AlH aetiology, its clinical presentation, diagnosis and treatment suffer similar ambivalent interpretations. Generally, AlH appears in most patients to be subtle and progresses gradually, presenting symptoms of chronic hepatic disease, acute liver failure or acute icteric hepatitis. ${ }^{20}$ In some cases, however, AlH presents random abnormal liver function tests or complications associated with portal hypertension like hypersplenism or gastrointestinal bleeding. ${ }^{21}$ Children exhibit a higher frequency of acute presentation relative to adults where onset is mostly subtle and subclinical. ${ }^{22}$

To date, there is no single diagnostic test for $\mathrm{AlH}$, however, diagnosis is mostly based on several symptomatic findings of serological, biochemical, histological, and clinical parameters. First, the presence of other causes of liver diseases must be identified and excluded. To simplify diagnosis of AlH, the IAIHG in 2008 devised a diagnostic scoring system for clinical use involving four major parameters: hypergammaglobulinemia (i.e. IgG > normal range = 1 point; IgG > $1.10 \times$ normal range $=2$ points), histology (i.e. compatible with $\mathrm{AlH}=1$ point; typical with $\mathrm{AlH}=2$ points), exclusion of viral hepatitis ( 2 points) and autoantibodies (i.e. $\geq 1: 40=1$ point; $\geq 1: 80=2$ points for any two of anti-nuclear antibody [ANA], anti-smooth muscle antibody [ASMA], anti-mitochondrial antibody [AMA] and anti-LKM-1). Scores $\geq 6$ denote probable AlH while scores $\geq 7$ are definitive of $\mathrm{AlH} .{ }^{23}$

Treatment of $\mathrm{AlH}$ targets induction of remission through suppression of inflammation to prevent further decompensation of liver and progression into cirrhosis. ${ }^{24}$ Azathioprine is mostly the drug of choice to induce remission and could be administered concurrently with the steroid prednisolone or after 2 weeks. In patients with steroid side effects, prednisolone can be replaced with synthetic 
glucocorticoid budesonide. Once remission is achieved, it can be maintained by azathioprine monotherapy. ${ }^{25}$ Other drugs include calcineurin inhibitors (cyclosporine and tacrolimus) as well as anti-TNF-a agents like infliximab. ${ }^{26,27}$ For trial withdrawal, over 2 years stable biochemical remission is required, although for most patients lifelong therapy is necessary. ${ }^{28,29}$

With the shortage in the availability of researched data on AlH especially in the Arab population, the present study aims at evaluating and documenting the experience of Iraqi AlH patients with respect to clinical presentation, diagnosis, treatment and by extension, response to treatment in accordance with the IAIHG guidelines.

\section{Materials and Methods}

We conducted a prospective study on 70 patients who attended the Gastroenterology Hepatology Teaching Hospital in Baghdad, Iraq between March 2017 and March 2018. The participants were enrolled based on suspicion of AlH upon the manifestation of jaundice, fatigue and/ or elevated liver enzymes. Patients were excluded from the study if evidence of viral hepatitis, Wilson's disease, alcoholic liver disease or a significant drug history was found.

The patients were subjected to a careful history-taking and physical examination after which venous blood samples were collected and the following laboratory data were collected: Liver function tests (serum alanine aminotransferase [ALT], aspartate aminotransferase [AST], alkaline phosphatase [ALP], and gamma-glutamyl transferase [GGT]) using kits from Biolyzer Lichtenfels, Germany, complete blood count, prothrombin time (from which the international normalized ratio [INR] was computed), serum protein electrophoresis, celiac disease antibodies (i.e. anti-tissue transglutaminase and anti-gliadin antibodies), immunological markers (ANA, ASMA, and AMA using Swelab Alfa haematology analyzer, Sweden, BIO-TP kit (BIOLABO SA, Maizy, France), and ELISA kits from AESKU company, Germany, respectively).

Samples that tested negative for the immunological markers were tested for anti-LKM-1, soluble liver antigen (SLA) and in some cases, perinuclear - antineutrophil cytoplasmic antibody (P-ANCA) which was measured using kits from Eurolmmun, a PerkinElmer Germany company.

Abdominal ultrasound was performed for all the patients and those who showed features of cirrhosis (from laboratory or ultrasound data) underwent upper endoscopic examination. Additionally, a biopsy of the liver was conducted on patients who consented to the procedure.

\section{Aih Diagnosis}

The data obtained from the above-mentioned analyses guided the diagnosis of AIH using the IAIHG's simplified international scoring system for AlH as detailed in Table 1. For patients exhibiting overlap syndrome between $\mathrm{AlH}$ and primary biliary cirrhosis (PBC), the criteria previously used were applied as shown below: ${ }^{28,30}$

For $\mathrm{AlH}$, any 2 out of the following 3 criteria were applied:

- ALT levels $>5$ ULN

- Serum IgG levels > 2 ULN or a positive test for ASMA

- Liver biopsy showing moderate or severe periportal or periseptal lymphocytic piecemeal necrosis

For PBC, any 2 out of the following 3 criteria were applied:

- $\mathrm{ALP}>2$ or $y$-glutamyltranspeptidase levels $>5$ ULN

- Positive test for AMA

- Liver biopsy specimen showing florid bile duct lesions

Table I.IAIHG's Simplified International Scoring System for AlH

\begin{tabular}{|c|c|c|c|}
\hline Parameter & Category & Variable & Score \\
\hline \multirow{4}{*}{ Autoantibodies } & ANA or SMA & $1: 40$ & 1 \\
\cline { 2 - 4 } & Anti-LKM1 & $\geq 1: 80$ & $2 *$ \\
\cline { 2 - 4 } & SLA & Positive & 2 \\
\hline \multirow{2}{*}{$\begin{array}{c}\text { Immunoglobulin } \\
\text { level }\end{array}$} & IgG & $>1 \times$ ULN & 1 \\
\cline { 2 - 4 } Histological \\
findings & $\begin{array}{c}\text { Morphologic } \\
\text { features }\end{array}$ & $\begin{array}{c}\text { Compatible } \\
\text { with AIH }\end{array}$ & 1 \\
\cline { 2 - 4 } & \multicolumn{2}{|c|}{$\begin{array}{c}\text { Typical of } \\
\text { AlH }\end{array}$} & 2 \\
\hline \multirow{2}{*}{\begin{tabular}{c} 
Aggregate score \\
\cline { 2 - 4 }
\end{tabular}} & \multicolumn{2}{|c|}{ Definite diagnosis } & $\geq 7$ \\
\cline { 2 - 4 } & \multicolumn{2}{|c|}{ Probable diagnosis } & 6 \\
\hline
\end{tabular}

ANA: anti-nuclear antibody, SMA: anti-smooth muscle antibody, antiLKM-1: anti- liver-kidney microsomal antibody type 1, SLA: soluble liver antigen, IgG: immunoglobulin G, AlH: autoimmune hepatitis. *Total points for all autoantibodies cannot exceed a maximum of 2 points. Compiled using information sourced from Hennes EM, Zeniya M et al. Hepatology 2008; 48: 169-176.

\section{Treatment Regimens}

The patients were started on Prednisone with a dose of $30-60 \mathrm{mg} /$ day in combination with azathioprine at a dose of 50 - $100 \mathrm{mg} /$ day, while maintenance doses were at 5-15 mg/day for prednisone and $50-100 \mathrm{mg} /$ day for azathioprine. All patients were kept on combined therapy with the exception of two patients who developed cytopenias and as a result, azathioprine was stopped and mycophenolate mofetil at a dosage of $500 \mathrm{mg}$ twice daily was administered as second-line therapy.

For patients with overlapping syndromes, ursodeoxycholic acid (UDCA) was administered at doses ranging from 300 mg twice to thrice daily. 


\section{Response to Treatment}

To ascertain response to treatment, biochemical remission characteristics as previously described by Manns et al., were utilised. Treatment response was considered complete if serum ALT dropped to the normal local laboratory range, within at least 6 months of treatment. Treatment response was considered partial if serum ALT does not normalise but decreases to less than $2 x$ the Upper Limit Normal (ULN) after 12 months of treatment. Patients who failed to achieve any reduction in serum ALT or who had an ALT elevation within 12 months of treatment were considered non-responders. ${ }^{31}$

Relapse was defined as an elevation of ALT to above normal local laboratory range or to the pretreatment level after an initial decrease. Progression to decompensated cirrhosis during the follow-up period was recorded.

\section{Results}

From our retrospective analysis, a total of 70 patients were diagnosed and included in the study. Fifty-five persons out of these patients had only AIH while 15 patients were diagnosed to have overlap syndrome. As presented in Table 2 , the participants included 54 females out of which 40 had only AlH while 14 had overlap syndrome, and 16 males, out of which 15 were diagnosed with only AlH while 1 patient showed overlap syndrome. The median age for AlH and overlap syndrome was 34 years and 38 years respectively. Figure 1 shows the frequency distribution of the patients' age range with patients between 30 and 39 years of age having the highest frequency (i.e. 18 persons representing $26 \%$ of the patients).

Table 2.Demographic, Clinical, Immunologic, and Histological Features of the Participants at Presentation

\begin{tabular}{|c|c|c|c|c|}
\hline \multicolumn{2}{|c|}{ Features } & All & AlH & Overlap \\
\hline \multicolumn{2}{|c|}{ Patients (n) } & 70 & 55 & 15 \\
\hline \multicolumn{2}{|c|}{ Age (years, median) } & 34 & 34 & 38 \\
\hline \multirow{2}{*}{$\begin{array}{l}\text { Gender } \\
\text { (n) }\end{array}$} & Female & 54 & 40 & 14 \\
\hline & Male & 16 & 15 & 1 \\
\hline \multirow{6}{*}{$\begin{array}{c}\text { Presenting } \\
\text { symptoms } \\
\text { (n) }\end{array}$} & Jaundice & 57 & 45 & 12 \\
\hline & Fatigue & 27 & 21 & 6 \\
\hline & Arthralgia & 14 & 14 & 0 \\
\hline & Itching & 23 & 16 & 7 \\
\hline & $\begin{array}{l}\text { Bleeding } \\
\text { tendency }\end{array}$ & 3 & 2 & 1 \\
\hline & $\begin{array}{l}\text { Decompensated } \\
\text { liver cirrhosis }\end{array}$ & 3 & 3 & 0 \\
\hline \multicolumn{2}{|c|}{ Family history of AlH (n) } & 7 & 4 & 3 \\
\hline
\end{tabular}

\begin{tabular}{|c|c|c|c|c|}
\hline \multirow{5}{*}{$\begin{array}{c}\text { Auto- } \\
\text { antibodies } \\
\text { (Positive } \\
\text { results } \\
\text { only, n) }\end{array}$} & ANA & 31 & 25 & 6 \\
\hline & ASMA & 25 & 23 & 2 \\
\hline & Anti-LKM1 & 3 & 3 & 0 \\
\hline & SLA & 2 & 2 & 0 \\
\hline & AMA & 8 & 0 & 8 \\
\hline \multicolumn{2}{|c|}{ Hypergammaglobulinemia (n) } & 68 & 53 & 15 \\
\hline \multirow{6}{*}{$\begin{array}{l}\text { Associated } \\
\text { immune } \\
\text { disease }(n)\end{array}$} & Thyroid & 4 & 4 & 0 \\
\hline & Diabetes & 2 & 2 & 0 \\
\hline & $\begin{array}{c}\text { Reumathoid } \\
\text { arthritis }\end{array}$ & 1 & 1 & 0 \\
\hline & Ulcerative colitis & 1 & 1 & 0 \\
\hline & Celiac disease & 1 & 1 & 0 \\
\hline & Cryoglobulinemia & 1 & 1 & 0 \\
\hline \multicolumn{2}{|c|}{ Interface hepatitis (n) } & 21 & 18 & 3 \\
\hline \multicolumn{2}{|c|}{ Billiary features (n) } & 1 & 0 & 1 \\
\hline
\end{tabular}

ANA: anti-nuclear antibody, SMA: anti-smooth muscle antibody, antiLKM-1: anti- liver-kidney microsomal antibody type 1, SLA: soluble liver antigen, IgG: immunoglobulin G, AIH: autoimmune hepatitis

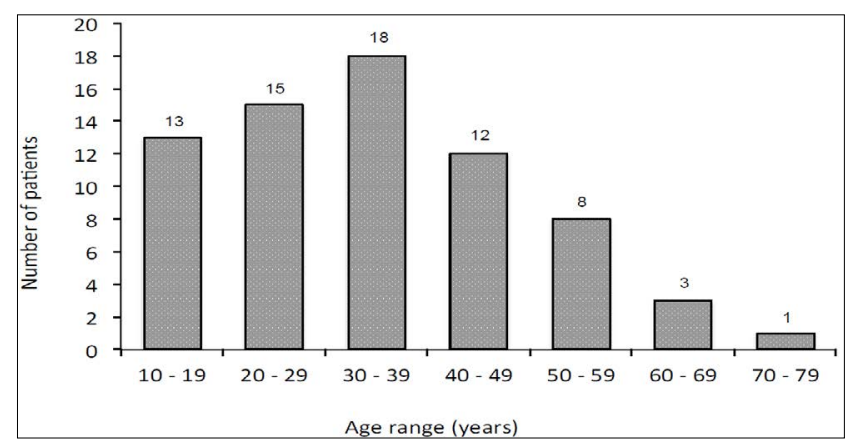

Figure I.Frequency distribution of the Patients as per their Age Range

Individuals between the ages of $30-39$ years (18 patients) formed the majority of the AlH patients with the age range of 20-29 years and 10-19 years having the 2 nd and 3 rd highest frequency. One of the patients was over 70 years of age.

\section{Patient Characteristics at Presentation}

At presentation (Table 1), the most common symptom recorded was jaundice which presented in 57 (81\%) patients (i.e. 45 patients for $\mathrm{AlH}$ and 12 patients for overlap syndrome). Others symptoms included fatigue (27 patients), arthralgia (14 patients), itching (23 patients), while bleeding tendency and decompensated liver cirrhosis was observed in 3 patients each. Seven patients had a family history of $\mathrm{AlH}$.

The main immunologic findings were positivity for ANA (i.e. 31 patients with 25 patients representing $35.7 \%$ have only $\mathrm{AIH}$ ) and positivity for ASMA in 25 patients, 23 of whom had only AlH. Nearly all the patients (68 persons 
representing 97\%) exhibited hypergammaglobulinemia. For associated autoimmune diseases, 4 patients were known cases of thyroid diseases, while 2 were diabetic and 1 patient was diagnosed for each of rheumatoid arthritis, ulcerative colitis, celiac disease, and cryoglobulinemia. Majority of the patients dissented from undergoing liver biopsy while those with decompensated liver cirrhosis were exempted. Thus, liver biopsy was only performed in 21 patients $(30 \%)$, all of which showed interface hepatitis with 18 for only AlH. Biliary features were detected in 1 patient with overlap syndrome.

\section{Scoring and Response to Treatment}

As shown in Figure 2, our pre-treatment scoring data indicated that 56 patients $(80 \%)$ were diagnosed with definite $\mathrm{AlH}$ and 14 patients (20\%) had probable $\mathrm{AlH}$. However, post-treatment scoring showed that 34 patients (approx. 49\%) scored below the diagnostic threshold for $\mathrm{AlH}$ (i.e. <6), 23 patients (33\%) fell within the diagnostic range of probable AlH while 13 patients were still definite $\mathrm{AlH}$.

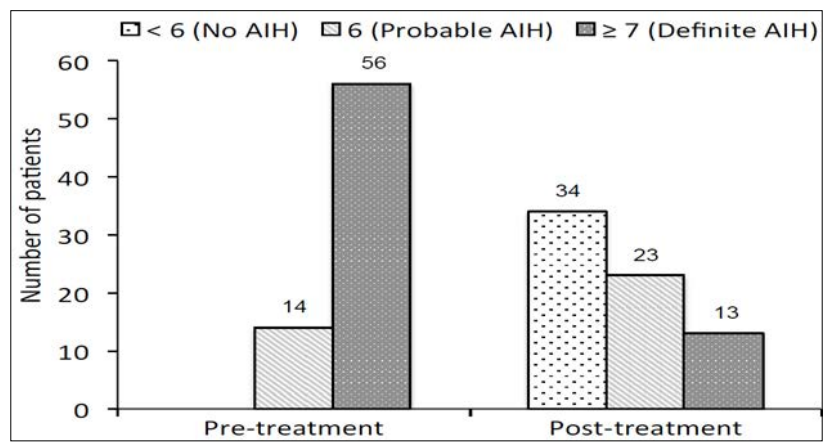

Figure 2.Diagnostic Scorning Data Before and After Treatment

Pre-treatment diagnostic scoring identified 14 patients with probable AlH and 56 patients with definite AlH. These values markedly changed in the post-treatment diagnostic scoring as 34 patients fell short of the $\mathrm{AlH}$ diagnostic threshold while 23 and 13 patients still had probably and definitive AlH respectively.

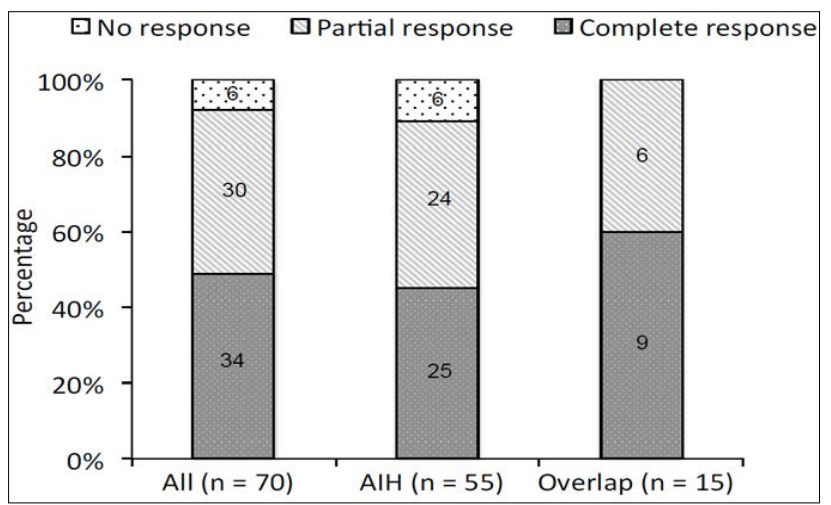

Figure 3.Response to Treatment for AlH and Overlap Patients
Findings from analysis of response to treatment however showed that although 6 patients all of which had only $\mathrm{AlH}$ were non-responders, 34 patients (49\%) exhibited complete response while 30 patients (43\%) partially responded to the treatment (Figure 3). All patients with overlapping syndrome showed response to UDCA with complete response recorded in 9 patients and partial response in 6 patients (Figure 3).

Complete response was observed in 34 patients while partial response was recorded in 30 patients and 6 patients were non-responders (all of which had AIH only). Response to UCDA in patients with overlap syndromes was $100 \%$ - 9 out of 15 patients completely responded to treatment with the remaining 6 as partial responders.

Table 3 shows a comparison between scoring diagnosis and response to treatment. Among the patients considered to have complete response to treatment, 10 patients showed probable AlH while 9 patients showed definite $\mathrm{AlH}$ based on the IAIHG scoring simplified system. For partial responders, 11 patients had probable $\mathrm{AlH}$ while definite AlH was observed in only 2 patients.

Table 3.Comparison between Scoring Diagnosis and Response to Treatment

\begin{tabular}{|c|c|c|c|c|}
\hline $\begin{array}{c}\text { Aggregate } \\
\text { Score }\end{array}$ & $\begin{array}{c}\text { Complete } \\
\text { Response } \\
\text { (n = 34) }\end{array}$ & $\begin{array}{c}\text { Partial } \\
\text { Response } \\
\text { (n= 30) }\end{array}$ & $\begin{array}{c}\text { No } \\
\text { Response } \\
\text { (n = 6) }\end{array}$ & $\begin{array}{c}\text { p- } \\
\text { value }\end{array}$ \\
\hline $\begin{array}{c}\text { < (No } \\
\text { AlH) }\end{array}$ & 15 & 17 & 3 & \\
\hline $\begin{array}{c}6 \\
\text { (Probable } \\
\text { AlH) }\end{array}$ & 10 & 11 & 2 & \multirow{2}{*}{0.1} \\
\cline { 1 - 2 } $\begin{array}{c}\text { (Definite } \\
\text { AlH) }\end{array}$ & 9 & 2 & 1 & \\
\hline
\end{tabular}

\section{Discussion}

The prevalence and clinical characteristics of AlH manifest with disparities among different regions globally. While regions such as Arabia, Africa, Asia, India, and South America experience disease onset at relatively younger ages, $\mathrm{AlH}$ occurs at older ages in Europe and North America. ${ }^{4}$ In this study, the median age of AlH patients at presentation was 34 years, which is similar to the mean age of 32 years previously reported by Fallatah et al. ${ }^{28}$ However, studies in New Zealand, Denmark, and the Netherlands reported peak onset age of 60-69 years, 70 years and $43-48$ years respectively. ${ }^{32-34}$ It has been suggested that incidence of elderly-onset $\mathrm{AlH}$ is associated with distinctive pathogenic characteristics such as age-related antigenic exposures and environmental agents, age-related immune dysfunction (immunosenescence), ${ }^{11}$ and genetic predisposition - a 
study identified DRB1*04 as the predominant genetic marker in patients with disease onset at 60 years and above. ${ }^{35}$ Kazuhiko Morii et al. associated elderly-onset AlH with higher levels of serum IgG, higher ANA levels, lesser hepatitis activity scores, and lesser chance of developing other autoimmune diseases. ${ }^{36}$ In our study, we recorded one patient above 70 years of age at presentation, the patient had an IgG level of 49.9 which is the highest recorded value.

Extensively across nearly all studies on $\mathrm{AlH}$, female predominance has been reported. This gender predilection occurs in patients of all ages as children with $\mathrm{AlH}$ were mostly girls than boys in studies conducted in the USA, ${ }^{37}$ Canada, ${ }^{38}$ and Great Britain. ${ }^{5}$ Very high female predisposition has been reported among adults in Alaskan natives (95\%) and Southern Isreal (95\%). ${ }^{39}$ The female to male ratio in our study was $3.4: 1$ i.e. $77 \%$ of the patients are females. Similar female predominance was reported in New Zealand (78\%), Denmark (72\%), and Sweden (78\%). ${ }^{11}$ Factors such as estrogen effects on cytokine pathways and gene expression as well as fetal microchimerism, variable X-chromosomal inactivation, and gender-biased intestinal dysbiosis have been identified as possible bases for the observed gender predominance in $\mathrm{AlH} .{ }^{40}$

The leading presenting symptoms observed in our study are jaundice which occurred in $80 \%$ of the patients, and fatigue which occurred in $30 \%$ of the patients. Although similar to our study, Tang et al., reported jaundice in $80 \%$ of Chinese $\mathrm{AlH}$ patients. ${ }^{41}$ the most prevailing symptom in studies conducted in the USA and Europe is fatigue rather than jaundice. ${ }^{42,43}$ The presentation of jaundice in AlH has been associated with disease severity, ${ }^{44}$ thus the possible explanation for this disparity in the leading presenting symptom may be that Iraqi patients tend to delay seeking medical consultation due to undiagnosed mild or asymptomatic AlH until disease severity develops and jaundice sets in. Other symptoms recorded in this study include itching (in $46 \%$ of patients), itching (in $33 \%$ of patients), Arthralgia (in 20\% of patients) and decompensated liver cirrhosis (in 3 patients, of which one is 72 years old) have also been reported by previous studies. ${ }^{45,46}$ Liver cirrhosis has been reported to be the mode of AlH presentation in $30 \%$ to $50 \%$ of patients while Czaja and Carpenter described a greater frequency of cirrhosis at presentation (33\%) in elderly patients. ${ }^{47,48}$ Delays in diagnosis resulting from low awareness of $\mathrm{AlH}$ among patients and doctors as well may be the major contributor to these presentations in Iraq.

Positivity for autoantibodies ANA, ASMA, anti-LKM, SLA, and AMA serve as important determinants in $\mathrm{AlH}$ diagnosis. The present study recorded positive ANA in $44 \%$ and positive ASMA in $35 \%$ of all the patients. These values are relatively smaller compared to those reported in previous studies. Fatalla et al., reported positive ANA in $87.8 \%$ and positive ASMA in $72.7 \%$ of Saudi Arabian patients ${ }^{28}$ while another study reported $67 \%$ for both ANA and ASMA positivity. ${ }^{49}$ The cumulative diagnostic value of these autoantibodies cannot exceed 2 points, owing to the enormity of their association with different variations in clinical presentations and prognosis of $\mathrm{AlH}$ - which led to the classification of AlH into Type 1 and Type $2 .{ }^{50}$ Type 1 AIH which is defined by positivity for ANA and ASMA, is associated with inflammatory activity in adult patients while type $2 \mathrm{AlH}$ which is defined by positivity for anti-LKM1, antiLKM3, and anti-liver cytosol antibodies, is more aggressive and is mostly common in children or younger patients. ${ }^{51}$

Hypergammaglobulinemia has been found to be the best diagnostic predictor of AlH. ${ }^{52}$ In our study, $97 \%$ of all patients had elevated levels of IgG i.e. above 1.44 UNL. High serum IgG values have been reported in $95 \%$ of patients and $61.5 \%$ of patients by previous studies. ${ }^{53,54}$ The IgG plays a significant role in the pathogenesis and diagnosis of $\mathrm{AlH}$ and as a result, IgG values along with transaminases are utilised as biomarkers for monitoring disease progress and response to treatment. ${ }^{55}$ Additionally, factors such as age, race, gender, and the environment, could influence the occurrence and nature of associated immune diseases in $\mathrm{AlH}$ patients. ${ }^{56}$ We reported 10 patients (14\%) having associated immune disorders most of which were thyroid related and diabetes. Studies have reported similar incidences of coexistence between AlH and immune disorders, especially in older patients. ${ }^{57,58}$ Also, studies have shown that the frequency of concurrent immune diseases is significantly affected by race as higher frequencies have been reported in Swedish patients (49\%) relative to Brazilian patients (14-18\%). ${ }^{59,60}$ We recorded a case of cryoglobulinemia through a skin biopsy. Numerous studies have reported that cryoglobulinemia syndrome might share a number of etio-pathogenetic events and clinical features with $\mathrm{AlH}$ as well as other autoimmune diseases and it tends to occur mostly in type $1 \mathrm{AlH}{ }^{61}$

Although histology may be recognised as the key to diagnosis of $\mathrm{AlH}$, its value has been questioned recently. Liver biopsy could provide vital information in certain situations where the available diagnostic findings are unsatisfactory, however, it is not possible to perform a liver biopsy in all cases for various reasons. ${ }^{62}$ Consistent with our findings, other studies have experience restrictions and were able to perform a liver biopsy in only one-third of cases of $\mathrm{AlH}$, due to the presence of cirrhosis in advanced stages, ascites, coagulopathy, or patient refusal. Lymphoplasmacytic infiltrate of the portal tracts and interface hepatitis are characteristic histologic elements of $\mathrm{AlH}$. Interface hepatitis was earlier reported in $65 \%$ of patients, including those with overlap AIH-PBC. ${ }^{48}$ Choudhuri et al. found this in 72.7\%, Bjornsson et al. in 95\%, and Gupta et al. and Abdollahi et al. found this in $100 \%$ 
of patients. ${ }^{56,63-65}$ Among the 21 patients that underwent liver biopsy in this study, interface hepatitis was found in $100 \%$ of the patients. It has been recognised that sample variability is amongst the main restrictions of liver biopsy and this may need further attention.

The present study observed that treatment with prednisone induced clinical and laboratory remission in 64 patients, of which 34 (48\%) completely responded while 30 (42\%) partially responded indicating a remission rate $(48.5 \%)$ lower than that reported in international studies. ${ }^{66}$ Although the complete response observed in this study was similar to that found by Fallatah et al. $(54.8 \%),{ }^{28}$ the partial response to treatment was also higher than expected $(42.8 \%) .{ }^{67}$ The possibility of a partial response to treatment is higher in young patients and in patients with a severe presentation or cirrhosis (cite). Treatment with UDCA in our patients with overlap syndrome has been associated with normalisation of ALP in 9 patients (60\%) while the other 6 patients showed partial response associated with a partial reduction in ALP levels with significant clinical response and these results were similar to that of previous studies. ${ }^{68-70}$

Subjecting our patients to post-treatment diagnosis scoring revealed an interesting outcome. Prior to treatment, 56 patients (80\%) had definite AlH while 14 (20\%) were probable AlH patients, however, after treatment, only 34 patients (48.5\%) scaled through the AlH diagnostic scoring threshold of less than 6 . Thirteen patients (18.5\%) and 23 patients (32.8\%) still fell within the definitive and probable AlH diagnostic scoring respectively. Since many of these patients have recorded good response to treatment and have had significantly reduced inflammatory features, the designation of definitive and/ or probable AIH is arbitrary and does not override clinical judgment. The relationship between scoring system and response to treatment showed that $26 \%$ of patients with complete response scored 7 and above while $29 \%$ of complete responders and as high as $36.6 \%$ of partial responders scored 6 . Statistical comparison of the responders between those two scores category indicated no significant difference ( $p$-value $=0.1$ ). This may either point to the need for further re-evaluation of the patients or the importance of a revised scoring system as proposed by other studies. ${ }^{71,72}$

\section{Conclusion}

The findings of our study are indicative that Iraqi patients with AlH presented late at the advanced stage of the disease. Thus hypergammaglobulinemia presented in the majority of the patients which forms the solid base for disease suspicion. Also, a significant number of patients refused liver biopsy, resulting in diagnosis and treatment delay as a large number of the patients are serologically negative.
Being a common disease, early diagnosis of AlH leads to significant prevention of serious complications. We, therefore, recommend that clinicians should render more attention to seronegative patients and encourage consent to liver biopsy especially in suspected cases. On the other hand, many cases of idiopathic hepatitis may be cases of $\mathrm{AlH}$ that require further investigations. Thus, our study may need further complementary study with a larger patient population, longer follow-up duration, and inclusion of cases of idiopathic hepatitis to confirm the results.

\section{Acknowledgments}

The authors wish to thank the Internal Medicine Department of the College of Medicine, University of Kerbala, and Gastroenterology \& Hepatology Centre, Imam Al-Hussein Medical City, Kerbala, Iraq for their support.

\section{Source of Funding: None \\ Conflict of Interest: None}

\section{References}

1. Harada K, Hiep NC, Ohira H. Challenges and difficulties in pathological diagnosis of autoimmune hepatitis. Hepatol Res. 2017;47(10):963-71. [PubMed] [Google Scholar]

2. Floreani $A$, Restrepo-Jiménez $P$, Secchi MF, De Martin S, Leung PS, Krawitt E, Bowlus CL, Greshwin ME, Anaya JM. Etiopathogenesis of autoimmune hepatitis. J Autoimmun. 2018;95:133-43. [PubMed] [Google Scholar]

3. Webb GJ, Hirschfield GM, Krawitt EL, Gershwin ME. Cellular and molecular mechanisms of autoimmune hepatitis. Annu Rev Pathol. 2018;13:247-92. [PubMed] [Google Scholar]

4. Ngu JH, Bechly K, Chapman BA, Burt MJ, Barclay ML, Gearry RB, Stedman CA. Population-based epidemiology study of autoimmune hepatitis: a disease of older women? J Gastroenterol Hepatol. 2010;25(10):1681-6. [PubMed] [Google Scholar]

5. Jiménez-Rivera C, Ling SC, Ahmed N, Yap J, Aglipay M, Barrowman N, Graitson S, Critch J, Rashid M, Ng VL, Roberts EA, Brill H, Dowhaniuk JK, Bruce G, Bax K, Deneau M, Guttman OR, Schreiber RA, Martin S, Alvarez $F$. Incidence and characteristics of autoimmune hepatitis. Pediatrics. 2015;136(5):e1237-e48. [PubMed] [Google Scholar]

6. Hurlburt KJ, McMahon BJ, Deubner H, Hsu-Trawinski B, Williams JL, Kowdley KV. Prevalence of autoimmune liver disease in Alaska Natives. Am J Gastroenterol. 2002;97(9):2402-7. [PubMed] [Google Scholar]

7. Primo J, Merino C, Fernandez J, Moles JR, Llorca P, Hinojosa J. [Incidence and prevalence of autoimmune hepatitis in the area of the Hospital de Sagunto (Spain)]. 
Gastroenterol Hepatol. 2004;27(4):239. Spanish. [PubMed] [Google Scholar]

8. Whalley S, Puvanachandra P, Desai A, Kennedy H. Hepatology outpatient service provision in secondary care: a study of liver disease incidence and resource costs. Clin Med. 2007;7(2):119. [PubMed] [Google Scholar]

9. Boberg K, Aadland E, Jahnsen J, Raknerud N, Stiris $\mathrm{M}$, Bell $\mathrm{H}$. Incidence and prevalence of primary biliary cirrhosis, primary sclerosing cholangitis, and autoimmune hepatitis in a Norwegian population. Scand J Gastroenterol. 1998;33(1):99-103. [PubMed] [Google Scholar]

10. Muslim OT, Taher AA. Association of anti-mitochonderial antibody (AMA), anti-soluble liver antigen (SLA) and HLA-DR3 in autoimmune hepatitis patients. Res J Pharma Tech. 2020;13(2):819-22. [Google Scholar]

11. Czaja AJ. Global disparities and their implications in the occurrence and outcome of autoimmune hepatitis. Dig Dis Sci. 2017;62(9):2277-92. [PubMed] [Google Scholar]

12. Lim KN, Casanova RL, Boyer TD, Bruno CJ. Autoimmune hepatitis in African Americans: presenting features and response to therapy. Am J Gastroenterol. 2001;96(12):3390-4. [PubMed] [Google Scholar]

13. Wen JW, Kohn MA, Wong R, Somsouk M, Khalili M, Maher J, Tana MM. Hospitalizations for autoimmune hepatitis disproportionately affect Black and Latino Americans. Am J Gastroenterol. 2018;113(2):243. [PubMed] [Google Scholar]

14. Moon AM, Singal AG, Tapper EB. Contemporary epidemiology of chronic liver disease and cirrhosis. Clin Gastroenterol Hepatol. 2020;18(12):2650-66. [PubMed] [Google Scholar]

15. Averbukh LD, Wu GY. Role of biologics in the development of autoimmune hepatitis: a review. J Clin TransI Hepatol. 2018;6(4):402. [PubMed] [Google Scholar]

16. Rojas $M$, Restrepo-Jiménez $P$, Monsalve DM, Pacheco Y, Acosta-Ampudia Y, Ramírez-Santana C, Leung PS, Ansari AA, Greshwin ME, Anaya JM. Molecular mimicry and autoimmunity. J Autoimmun. 2018;95:100-23. [PubMed] [Google Scholar]

17. Christen U, Hintermann E. Pathogens and autoimmune hepatitis. Clin Exp Immunol. 2019;195(1):35-51. [PubMed] [Google Scholar]

18. Liberal R, Grant CR, Longhi MS, Mieli-Vergani G, Vergani D. Diagnostic criteria of autoimmune hepatitis. Autoimmun Rev. 2014;13(4-5):435-40. [PubMed] [Google Scholar]

19. Heneghan $M A$, Yeoman $A D$, Verma $S$, Smith $A D$, Longhi MS. Autoimmune hepatitis. Lancet. 2013;382(9902):1433-44. [Google Scholar]

20. Manns MP, Vogel A. Autoimmune hepatitis, from mechanisms to therapy. Hepatology. 2006;43(S1):S132-S44. [PubMed] [Google Scholar]

21. McCormick PA, Murphy KM. Splenomegaly, hypersplenism and coagulation abnormalities in liver disease. Baillieres Best Pract Res Clin Gastroenterol. 2000;14(6):1009-31. [PubMed] [Google Scholar]

22. Pathak $S$, Kamat D. Autoimmune hepatitis in children. Pediatr Ann. 2018;47(2):e81-e6. [PubMed] [Google Scholar]

23. Alvarez F, Berg PA, Bianchi FB, Bianchi L, Burroughs AK, Cancado EL, Chapman RW, Cooksley WG, Czaja AJ, Desmet VJ, Donaldson PT, Eddleston AL, Fainboim L, Heathcote J, Homberg JC, Hoofnagle JH, Kakumu S, Krawitt EL, Mackay IR, MacSween RN, Maddrey WC, Manns MP, McFarlane IG, Buschenfelde KH, Zeniya M. International Autoimmune Hepatitis Group Report: review of criteria for diagnosis of autoimmune hepatitis. J Hepatol. 1999;31(5):929-38. [PubMed] [Google Scholar]

24. Beretta-Piccoli BT, Mieli-Vergani G, Vergani D. Autoimmune hepatitis: standard treatment and systematic review of alternative treatments. World J Gastroenterol. 2017;23(33):6030. [PubMed] [Google Scholar]

25. McNally BB, Carey EJ. Azathioprine monotherapy is equivalent to dual therapy in maintaining remission in autoimmune hepatitis. Dig Dis Sci. 2020;66(5):1715-9. [PubMed] [Google Scholar]

26. Pape $S$, Nevens F, Verslype $C$, Mertens $C$, Drenth JP, Tjwa ET. Profiling the patient with autoimmune hepatitis on calcineurin inhibitors: a real-world-experience. Eur J Gastroenterol Hepatol. 2020;32(6):727. [PubMed] [Google Scholar]

27. Corrigan M, Haydon G, Thompson F, Rajoriya N, Peplow $\mathrm{CL}$, Hubscher SG, Steven N, Hirschfield GM, Armstrong $\mathrm{MJ}$. Infliximab for the treatment of refractory immunerelated hepatitis secondary to checkpoint inhibitors: a case report. JHEP Rep. 2019;1(1):66-9. [PubMed] [Google Sholar]

28. Fallatah HI, Akbar HO, Qari YA. Autoimmune hepatitis: single-center experience of clinical presentation, response to treatment and prognosis in Saudi Arabia. Saudi J Gastroenterol. 2010;16(2):95. [PubMed] [Google Scholar]

29. Czaja AJ, Freese DK. Diagnosis and treatment of autoimmune hepatitis. Hepatology. 2002;36(2):47997. [Google Scholar]

30. Nguyen HH, Shaheen AA, Baeza N, Lytvyak E, Urbanski SJ, Mason AL, Norman GL, Fritzler MJ, Swain MG. Evaluation of classical and novel autoantibodies for the diagnosis of Primary Biliary Cholangitis-Autoimmune Hepatitis Overlap Syndrome (PBC-AIH OS). PloS One. 2018;13(3):e0193960. [PubMed] [Google Scholar] 
31. Russo MW. Diagnosis and management of autoimmune hepatitis: a clinical guide. Springer Nature; 2020. [Google Scholar]

32. Van Gerven NM, Verwer BJ, Witte BI, van Erpecum $\mathrm{KJ}$, van Buuren HR, Maijers I, Visscher AP, Verschuren EC, van Hoek B, Coenraad MJ, Beuers UH, de Man RA, Drenth JP, den Ouden JW, Verdonk RC, Koek GH, Brouwer JT, Guichelaar MM, Vrolijk JM, Mulder CJ, van Nieuwkerk CM, Bouma G; Dutch Autoimmune hepatitis STUDY group. Epidemiology and clinical characteristics of autoimmune hepatitis in the Netherlands. Scand J Gastroenterol. 2014;49(10):1245-54. [PubMed] [Google Scholar]

33. Grønbæk L, Vilstrup H, Jepsen P. Autoimmune hepatitis in Denmark: incidence, prevalence, prognosis, and causes of death. A nationwide registry-based cohort study. J Hepatol. 2014;60(3):612-7. [PubMed] [Google Scholar]

34. Czaja AJ. Transitioning from idiopathic to explainable autoimmune hepatitis. Dig Dis Sci. 2015;60(10):2881900. [PubMed] [Google Scholar]

35. Czaja AJ, Carpenter HA. Distinctive clinical phenotype and treatment outcome of type 1 autoimmune hepatitis in the elderly. Hepatology. 2006;43(3):532-8. [PubMed] [Google Scholar]

36. Morii K, Nagano Y, Yamamoto T, Nakamura S, Okushin $\mathrm{H}$. Increasing incidence of elderly-onset autoimmune hepatitis. Geriatr Gerontol Int. 2017;17(10):1722-8. [PubMed] [Google Scholar]

37. Deneau M, Jensen MK, Holmen J, Williams MS, Book LS, Guthery SL. Primary sclerosing cholangitis, autoimmune hepatitis, and overlap in Utah children: epidemiology and natural history. Hepatology. 2013;58(4):1392-400. [PubMed] [Google Scholar]

38. Gregorio GV, Portmann B, Reid F, Donaldson PT, Doherty DG, McCartney M, Mowat AP, Vergani D, Mieli-Vergani G. Autoimmune hepatitis in childhood: a 20-year experience. Hepatology. 1997;25(3):541-7. [PubMed] [Google Scholar]

39. Delgado JS, Vodonos A, Malnick S, Kriger O, WilkofSegev R, Delgado B, Novack V, Rosenthal A, Menachem $\mathrm{Y}$, Melzer E, Fich A. Autoimmune hepatitis in southern Israel: a 15-year multicenter study. J Dig Dis. 2013;14(11):611-8. [PubMed] [Google Scholar]

40. Khera S, Saigal A. Autoimmune diseases and their prevalence in females: a review. Int J Health Sci Res. 2017;7(7).

41. Tang CP, Shiau YT, Huang YH, Tsay SH, Huo TI, Wu JC, Lin $\mathrm{HC}$, Lee SD. Cholestatic jaundice as the predominant presentation in a patient with autoimmune hepatitis. J Chin Med Assoc. 2008;71(1):45-8. [PubMed] [Google Scholar]

42. Swain MG, Jones DE. Fatigue in chronic liver disease: new insights and therapeutic approaches. Liver Int. 2019;39(1):6-19. [PubMed] [Google Scholar]

43. Gordon V, Adhikary R, Appleby V, Das D, Day J, Delahooke T, Dixon S, Elphick D, Hardie C, Hoeroldt B, Hooper P, Hutchinson J, Jones R, Khan F, Aithal GP, McGonigle J, Nelson A, Nkhoma A, Pelitari S, Prince M, Prosser A, Sathanarayana V, Savva S, Shah N, Saksena S, Thayalasekaran S, Vani D, Yeoman A, Gleeson D; UK Multi-Centre AlH Audit Group. Diagnosis, presentation and initial severity of autoimmune hepatitis $(\mathrm{AlH})$ in patients attending 28 hospitals in the UK. Liver Int. 2018;38(9):1686-95. [PubMed] [Google Scholar]

44. Pape S, Schramm C, Gevers TJ. Clinical management of autoimmune hepatitis. United European Gastroenterol J. 2019;7(9):1156-63. [PubMed [Google Scholar]

45. Mack CL, Adams D, Assis DN, Kerkar N, Manns MP, Mayo MJ, Vierling JM, Alsawas M, Murad MH, Czaja AJ. Diagnosis and management of autoimmune hepatitis in adults and children: 2019 practice guidance and guidelines from the American Association for the Study of Liver Diseases. Hepatology. 2020;72(2):671-722. [PubMed] [Google Scholar]

46. Jeimy S, McRae K, Pattani R. A 63-year-old returned traveller with fever, rash, hepatitis and eosinophilia. CMAJ. 2018;190(27):E831-E5. [PubMed] [Google Scholar]

47. Wang $Z$, Sheng $L$, Yang $Y$, Yang $F$, Xiao $X$, Hua J, Guo C, Wei Y, Tang R, Miao Q, Zhang J, Li Y, Fang J, Qiu D, Krawitt EL, Bowlus CL, Gershwin ME, Wang Q, Ma X. The management of autoimmune hepatitis patients with decompensated cirrhosis: real-world experience and a comprehensive review. Clin Rev Allergy Immunol. 2017;52(3):424-35. [PubMed] [Google Scholar]

48. Czaja AJ, Carpenter HA. Autoimmune hepatitis overlap syndromes and liver pathology. Gastroenterol Clin North Am. 2017;46(2):345-64. [PubMed] [Google Scholar]

49. Shibuki T, Otsuka T, Isoda $H$, Araki N, Kubotsuv $Y$, Kawaguchi Y, Nakashita S, Yoshioka W, Kawazoe S, Kawasoe H, Ide Y, Mizuta T; Saga Study Group of Liver Diseases Sasld. Seropositivity and titers of anti-smooth muscle actin antibody are associated with relapse of type 1 autoimmune hepatitis. Med Sci Monit. 2017;23:4028. [PubMed] [Google Scholar]

50. Muratori P, Lalanne C, Fabbri A, Cassani F, Lenzi M, Muratori L. Type 1 and type 2 autoimmune hepatitis in adults share the same clinical phenotype. Aliment Pharmacol Ther. 2015;41(12):1281-7. [PubMed] [Google Scholar]

51. Muratori L, Cataleta M, Muratori P, Lenzi M, Bianchi F. Liver/kidney microsomal antibody type 1 and liver cytosol antibody type 1 concentrations in type 2 autoimmune hepatitis. Gut. 1998;42(5):721-6. 
[PubMed] [Google Scholar]

52. Beretta-Piccoli BT, Mieli-Vergani G, Vergani D. The clinical usage and definition of autoantibodies in immune-mediated liver disease: a comprehensive overview. J Autoimmun. 2018;95:144-58. [PubMed] [Google Scholar]

53. Galaski J, Weiler-Normann C, Schakat M, Zachou K, Muratori P, Lampalzer S, Haag F, Schramm C, Lenzi M, Dalekos GN, Lohse AW. Update of the simplified criteria for autoimmune hepatitis: evaluation of the methodology for immunoserological testing. J Hepatol. 2021;74(2):312-20. [PubMed] [Google Scholar]

54. Biewenga M, Inderson A, Tushuizen ME, Crobach ASL, van Hoek $B$. Early predictors of short-term prognosis in acute and acute severe autoimmune hepatitis. Liver Transpl. 2020;26(12):1573-81. [PubMed] [Google Scholar]

55. Yuan X, Duan SZ, Cao J, Gao N, XU J, Zhang L. Noninvasive inflammatory markers for assessing liver fibrosis stage in autoimmune hepatitis patients. Eur J Gastroenterol Hepatol. 2019;31(11):1467. [PubMed] [Google Scholar]

56. Abdollahi MR, Somi MH, Faraji E. Role of international criteria in the diagnosis of autoimmune hepatitis. World J Gastroenterol. 2013;19(23):3629. [PubMed] [Google Scholar]

57. Wong GW, Heneghan MA. Association of extrahepatic manifestations with autoimmune hepatitis. Dig Dis. 2015;33(Suppl. 2):25-35. [PubMed] [Google Scholar]

58. Szyper-Kravitz M, Marai I, Shoenfeld Y. Coexistence of thyroid autoimmunity with other autoimmune diseases: friend or foe? Additional aspects on the mosaic of autoimmunity. Autoimmunity. 2005;38(3):247-55. [PubMed] [Google Scholar]

59. Werner M, Prytz H, Ohlsson B, Almer S, Björnsson $E$, Bergquist $A$, Wallerstedt $S$, Sandberg-Gertzen $H$, Hultcrantz R, Sangfelt $P$, Weiland $O$, Danielsson A. Epidemiology and the initial presentation of autoimmune hepatitis in Sweden: a nationwide study. Scand J Gastroenterol. 2008;43(10):1232-40. [PubMed] [Google Scholar]

60. Bittencourt PL, Farias AQ, Porta G, Cancado EL, Miura I, Pugliese R, Kalil J, Goldberg AC, Carrilho FJ. Frequency of concurrent autoimmune disorders in patients with autoimmune hepatitis: effect of age, gender, and genetic background. J Clin Gastroenterol. 2008;42(3):300-5. [PubMed] [Google Scholar]

61. Desbois AC, Cacoub P, Saadoun D. Cryoglobulinemia: an update in 2019. Joint Bone Spine. 2019;86(6):70713. [PubMed] [Google Scholar]

62. Davison BA, Harrison SA, Cotter G, Alkhouri N, Sanyal A, Edwards C, Colca JR, Iwashita J, Koch GG, Dittrich HC. Suboptimal reliability of liver biopsy evaluation has implications for randomized clinical trials. J Hepatol.
2020;73(6):1322-32. [PubMed] [Google Scholar]

63. Choudhuri G, Somani SK, Baba CS, Alexander G. Autoimmune hepatitis in India: profile of an uncommon disease. BMC Gastroenterol. 2005;5(1):27. [PubMed] [Google Scholar]

64. Björnsson E, Talwalkar J, Treeprasertsuk S, Neuhauser $M$, Lindor K. Patients with typical laboratory features of autoimmune hepatitis rarely need a liver biopsy for diagnosis. Clin Gastroenterol Hepatol. 2011;9(1):57-63. [PubMed] [Google Scholar]

65. Gupta R, Agarwal SR, Jain M, Malhotra V, Sarin SK. Autoimmune hepatitis in the Indian subcontinent: 7 years experience. J Gastroenterol Hepatol. 2001;16(10):1144-8. [PubMed] [Google Scholar]

66. Tanaka A. Autoimmune Hepatitis: 2019 Update. Gut Liver. 2020;14(4):430-8. [PubMed [Google Scholar]

67. D'Souza R, Sinnott P, Glynn MJ, Sabin CA, Foster GR. An unusual form of autoimmune hepatitis in young Somalian men. Liver Int. 2005;25(2):325-30. [PubMed] [Google Scholar]

68. Trivedi PJ, Hubscher SG, Heneghan M, Gleeson D, Hirschfield GM. Grand round: autoimmune hepatitis. J Hepatol. 2019;70(4):773-84. [PubMed] [Google Scholar]

69. To U, Silveira M. Overlap syndrome of autoimmune hepatitis and primary biliary cholangitis. Clin Liver Dis. 2018;22(3):603-11. [PubMed] [Google Scholar]

70. Mago S, Wu GY. Primary sclerosing cholangitis and primary biliary cirrhosis overlap syndrome: a review. J Clin Transl Hepatol. 2020;8(3):336. [PubMed] [Google Scholar]

71. Lowe D, John S. Autoimmune hepatitis: appraisal of current treatment guidelines. World J Hepatol. 2018;10(12):911. [PubMed] [Google Scholar]

72. Teschke R, Eickhoff A, Brown AC, Neuman MG, Schulze J. Diagnostic biomarkers in liver injury by drugs, herbs, and alcohol: tricky dilemma after EMA correctly and officially retracted letter of support. Int J Mol Sci. 2020;21(1):212. [PubMed] [Google Scholar] 